(2) Open Access Full Text Article

ORIGINAL RESEARCH

\title{
Impact of IVF on the Timing and Symptoms of Menopause
}

\author{
R Muharam (D) \\ Kanadi Sumapraja (iD \\ Gita Pratama (D) \\ Mazaya Azyati (D) \\ Kevin Ardito Prabowo
}

Department of Obstetrics \& Gynecology, Faculty of Medicine, University of Indonesia, Cipto Mangunkusumo National Hospital, Jakarta, Indonesia
Correspondence: R Muharam

Department of Obstetrics \& Gynecology, Faculty of Medicine, University of

Indonesia, Cipto Mangunkusumo National Hospital, Jl. Pangeran Diponegoro No. 7I,

Kenari, Kec. Senen, Kota Jakarta Pusat,

Daerah Khusus Ibukota Jakarta, Jakarta,

10430, Indonesia

Tel +62 8I285I4349l

Email rmuharam@yahoo.com
Background: Age-related loss of female fertility is characterized by a decline in both the quantity and quality of ovarian follicles. Symptoms of ovarian stimulation, which is part of the process of in vitro fertilization (IVF), vary among women. This study was conducted to analyze the differences in menopausal timing and symptoms in women who had undergone IVF compared to those who had natural pregnancies.

Methodology: In this cross-sectional study, menopausal women were categorized into two groups: those who had undergone IVF $(n=50)$ and those who had not $(n=50)$. Clinical data were obtained from the participants' medical records, and patient interviews were conducted using the menopause rating scale (MRS) questionnaires.

Results: The IVF had no significant impact on psychological or somatic symptoms in either group ( $>0.05)$. However, it affected urogenital symptoms $(p<0.05)$. Additionally, there was a significant difference in the age of onset of menopause between the groups $(p<0.05)$.

Conclusion: There is a significant correlation between IVF treatment, urogenital symptoms in menopause, and the age of onset of menopause.

Keywords: in vitro fertilization, menopause, infertility, psychological symptoms, urogenital

\section{Introduction}

Infertility refers to the inability of a couple to achieve pregnancy after at least 12 months of regular sexual intercourse without the use of contraception. ${ }^{1}$ Cause of female infertility are divided into three groups, namely, ovulation, tubal and pelvic, and uterine disorders. Ovulation disorders, which are often accompanied by menstrual disorders, have an incidence of $30 \%{ }^{2}$ Couples who experience infertility often undergo a lengthy evaluation and treatment process, which can be physically and psychologically burdensome. ${ }^{3}$ One of these treatments is in vitro fertilization (IVF).

One of the key steps of IVF is ovarian stimulation, a procedure that is performed to produce and generate as many mature eggs as possible in order to increase the odds of conception. Ovarian stimulation is performed using exogenous gonadotropin preparations or by increasing endogenous gonadotropin secretion through the administration of ovulation-inducing drugs. ${ }^{4}$

The follicular utilization program through recruitment, growth, and atresia are set in the mid-to-late stages of follicular development by pituitary gonadotropins. ${ }^{5}$ Antral follicle count is a biomarker of reproductive age; ${ }^{6}$ thus, the number of oocytes harvested per cycle of IVF treatment is a predictor of the time of onset of menopause, although its precision is low. ${ }^{7,8}$ Follicles cannot be produced or changed, and menopause occurs when the numbers of follicles have reduced to a very low threshold of about 1.000 ; therefore, ovarian stimulation may accelerate 
the time of onset of menopause. ${ }^{9}$ Although the side effects are much less severe than cancer, the potential impact of gonadotropin therapy cannot be ignored because early menopause restricts reproductive potential, affects sexual health, and increases the risk of cardiovascular and metabolic disorders. ${ }^{10,11}$

Many patients who underwent IVF in the 2000s and early 2010s have now reached menopausal age. To the best of our knowledge, the long-term effect of IVF on the onset and symptoms of menopause have not been well-studied. Data in Indonesia stated that by 2020, the population of menopausal women aged 40-65 years will increase by $29,021,128(11.4 \%)$ from $7,998,543(5.5 \%)$ in $1980 .^{12}$ This demonstrates the magnitude of the problem. Therefore, the aim of this study was to analyze the differences in menopausal timing and symptoms in women who had undergone IVF compared to those of women who had natural pregnancies.

\section{Methods}

This research was conducted from August 2020 to August 2021 at the Cipto Mangunkusumo National Referral Hospital (RSCM) Jakarta.

This cross-sectional study compared menopausal women who had undergone IVF (the IVF group) with those who had never undergone IVF (the non-IVF group). The required total sample size was calculated using Slovin's formula to be between 96 and 100 patients; therefore, we included 50 participants in each group. Participants were recruited among patients who had undergone IVF at Yasmin Clinic, RSCM, between January 2010 and December 2015. Participants were considered eligible upon meeting the following criteria: 1) women over 45 years of age who had experienced menopause or had complaints of menopausal symptoms and had never undergone IVF; and 2) women who had undergone IVF using antagonist protocol. The IVF group comprised women who had undergone IVF. The exclusion criteria included women who had malignancies, women who did not use the antagonist protocol, and women who were unwilling to participate in the study.

Sampling was carried out using the medical records of female patients belonging to both groups. From the medical records, we obtained phone number of the patients. The tool used for obtaining data was a questionnaire: Patients in both groups, comprising those who underwent and those who did not undergo IVF, were interviewed by phone and the results were written by the interviewer. The questionnaire was divided into two parts. Briefly, the first part addressed menstrual and reproductive history, infertility treatment, medical history, and lifestyle factors. The second part contained the menopause rating scale (MRS; obtained from http://www.menopauserating-scale.info/) that focused on menopausal and perimenopausal symptoms. The questions had been translated to Indonesian as per international standards. ${ }^{12}$ The symptoms investigated were psychological, somatic, and urogenital. Menopause was conventionally defined as 12 or more months of continuous amenorrhea with no apparent cause other than age. In a few cases, further clarification was required, and patients were contacted again by phone.

This study was approved by the ethics committee of the faculty of medicine, University of Indonesia (Study number: $\quad$ KET-1165/UN2.F1/ETIK/PPM.00.02/2020). Informed consent was obtained from all patients. This study was conducted in accordance with the principles of the Declaration of Helsinki.

Statistical analysis was conducted using SPSS version 23.0 (IBM, Armonk, NY, USA). Demographic data were presented as mean \pm standard deviation. The comparison between the two groups was investigated using a nonparametric Mann-Whitney test. A p-value of $<0.05$ was considered significant.

\section{Results}

The participants' demographic characteristics are shown in Table 1. There were significant differences in age, number of children, menarche, previous medical history, marital status, and education between both groups $(\mathrm{p}<0.05)$. There were also data the age of IVF, number of IVF cycle, and smoking history.

Based on the MRS questionnaire, there was no significant impact on psychological and somatic symptoms in either group ( $>0.05$ ). Psychological symptoms such as depressive mood, irritability, anxiety and physical and mental exhaustion; somatic symptoms such as hot flushes, coronary discomfort, sleeping problems and muscle and joint problems. Nonetheless, there was a significant impact on urogenital symptoms in both groups (mean 44.33 vs $56.67, \mathrm{p}<0.05$; see Table 2). Urogenital symptoms such as sexual problems, bladder problems, and vaginal dryness. Additionally, there was a statistically significant difference in the age of onset of menopause between the IVF and the non-IVF groups (mean 49.84 vs 50.66 , respectively, $\mathrm{p}<0.05$ ).

Multivariate analysis demonstrated that none of the characteristic variables were independently associated with the severity of menopausal symptoms ( $p>0.05$; see 
Table I Characteristics of IVF and Non-IVF Patients

\begin{tabular}{|l|l|l|l|}
\hline Characteristics & IVF (n= 50) & Non-IVF (n = 50) & p-value \\
\hline $\begin{array}{l}\text { Age (mean } \pm \text { SD) } \\
\text { Age of IVF } \\
\text { Number of IVF cycle }\end{array}$ & $\begin{array}{l}51.02 \pm 2.42 \\
41.26 \pm 2.32\end{array}$ & $52.76 \pm 2.37$ & $0.000^{*}$ \\
\hline Number of children & $0.78(0-2)$ & $2.72(1-6)$ & $0.000^{* *}$ \\
\hline Menarche (mean \pm SD) & $13 \pm 0.94$ & $12.32 \pm 1.23$ & $0.003^{*}$ \\
\hline Onset age of menopause & 49.84 & 50.66 & 0.004 \\
\hline $\begin{array}{l}\text { Smoking history } \\
\text { Yes }\end{array}$ & $5(5 \%)$ & $3(3 \%)$ & $0.46 I^{* * *}$ \\
\hline $\begin{array}{l}\text { No } \\
\text { Previous surgical history } \\
\text { Yes } \\
\text { No }\end{array}$ & $\begin{array}{l}18(18 \%) \\
32(32 \%)\end{array}$ & $\begin{array}{l}7(7 \%) \\
43(43 \%)\end{array}$ & $0.011^{* * *}$ \\
\hline $\begin{array}{l}\text { Education } \\
\text { Senior high school } \\
\text { Diploma } \\
\text { Magister } \\
\text { Doctor }\end{array}$ & $\begin{array}{l}42(42 \%) \\
4(4 \%) \\
4(4 \%)\end{array}$ & $\begin{array}{l}17(14(14 \%) \\
4(4 \%)\end{array}$ & $0.000^{* * *}$ \\
\hline
\end{tabular}

Notes: *Independent Samples $t$-test, **Mann-Whitney test, ${ }^{* * *}$ Chi-square.

Table 2 Comparison Between IVF and Non-IVF Patients

\begin{tabular}{|l|l|l|l|}
\hline Variable & $\begin{array}{l}\text { IVF } \\
(\mathbf{n}=\mathbf{5 0}) *\end{array}$ & $\begin{array}{l}\text { Non-IVF } \\
(\mathbf{n}=\mathbf{5 0})\end{array}$ & $\mathbf{p}^{* * *}$ \\
\hline Somatic symptoms & 51.59 & $49.4 \mathrm{I}$ & 0.701 \\
Psycho symptoms & 48.04 & 52.96 & 0.386 \\
Urogenital symptoms & 44.33 & 56.67 & 0.030 \\
\hline
\end{tabular}

Note: *Mean, **Mann-Whitney test.

Table 3). Therefore, the differences in the baseline characteristics of both groups were negligible.

\section{Discussion}

The ovaries age over time and eventually lose their function, as menopause marks the definite end of a woman's reproductive life. The ovarian aging concept of reproduction assumes that the age-related loss of female fertility is determined by a decrease in the quantity and quality of ovarian follicles. The number of ovarian follicles in women with regular menstrual cycles (premenopausal) are ten times higher than those of perimenopausal women of the same age, whereas follicles are almost absent in postmenopausal women.

In this study, although IVF significantly impacted earlier menopausal age, we also found that there was a relationship between urogenital symptoms of menopause and IVF. Early menopausal symptoms occur before the age of 46; thus, women experiencing these symptoms might be at risk of early ovarian aging. ${ }^{13}$ Women who respond poorly to controlled ovarian hyperstimulation during IVF treatment, as indicated by low numbers of retrieved oocytes, have impaired ovarian reserve and are at risk of early menopause compared to women who have a normal response. ${ }^{14}$ This theoretical effect could result from accelerating the small follicle recruitment process or by increasing the rate of oocyte elimination or atresia.

Elder et al found no evidence that ovarian stimulation advances menopausal age in patients who had received fertility treatment. ${ }^{7}$ No significant adverse association was found in the study between the numbers of oocytes harvested and early menopausal symptoms, possibly because more aggressive stimulation protocols were used in an attempt to produce larger oocyte harvest. Women should be informed that all procedures involved in the process of IVF treatment are generally safe and do not place women at risk of premature ovarian failure.

A study by Heijnen et al revealed that the administration of gonadotropins for fertility treatment did not appear to have a long-term impact on ovarian aging or the timing or symptoms of menopause. Based on a study by Boer et al, the association between the number of retrieved oocytes at the first IVF treatment and early menopausal transition was weak, although significant. Their results showed that women with a low oocyte counts taken at first IVF treatment had an increased risk of achieving menopausal transition or natural menopause within a decade after the first IVF treatment. ${ }^{8}$ In the future, milder treatment strategies should be offered to patients undergoing IVF to prevent the risk of developing short-term or long-term side effects. ${ }^{15}$

Urogenital symptoms of menopause include various menopausal symptoms and signs that are associated with physical changes in the vulva, vagina, and lower urinary tract. These symptoms are related to postmenopausal reduction in the level of circulating estrogen. After menopause, the number of estrogen receptors continues to decrease; however, they never disappear completely. Although these problems are not life threatening, they may have an impact on a woman's quality of life. ${ }^{16}$ For example, the prevalence of women with endometriosis decreases with age since the age of menopause is variable and ovarian activity can be increased in the first year after menopause. ${ }^{17}$ A retrospective cohort study in the United Kingdom showed that women with poor ovarian response to gonadotrophins stimulation (three oocytes) are 
Table 3 Multivariate Analysis of Symptoms of IVF and Non-IVF Patients

\begin{tabular}{|l|l|l|}
\hline Variable & Unstandardized $\boldsymbol{\beta}$ Coefficient (95\% CI) & p-value* \\
\hline Somatic Symptoms & & \\
Age & $0.133(0.005-0.26 I)$ & 0.042 \\
Number of children & $-0.161(-0.435-0.113)$ & 0.247 \\
Menarche & $0.081(-0.215-0.378)$ & 0.587 \\
Previous surgical history & $-0.032(-0.769-0.705)$ & 0.932 \\
Education & $-0.061(-0.468-0.346)$ & 0.767 \\
\hline Psycho Symptoms & & \\
Age & $0.119(-0.032-0.269)$ & 0.120 \\
Number of children & $0.000(-0.322-0.323)$ & 0.998 \\
Menarche & $-0.35(-0.384-0.313)$ & 0.841 \\
Previous surgical history & $0.322(-0.544-1.189)$ & 0.462 \\
Education & $-0.449(-0.928-0.030)$ & 0.066 \\
\hline Urogenital Symptoms & & \\
Age & $0.072(-0.047-0.192)$ & 0.232 \\
Number of children & $0.082(-0.174-0.338)$ & 0.525 \\
Menarche & $0.041(-0.236-0.318)$ & 0.769 \\
Previous surgical history & $-0.223(-0.911-0.466)$ & 0.525 \\
Education & $0.072(-0.309-0.452)$ & 0.708 \\
\hline
\end{tabular}

Note: *Data analysis using linear regression, significant $p<0.05$.

more likely to experience early menopause than those with a good response (6-15 oocytes).

The limitation of this study is that there is a recall bias. Contacting women at least 10 years after their IVF treatment has been impossible in some cases. ${ }^{18}$ However, to the best of our knowledge, this is the first study to research this topic in Indonesia. Further research to investigate the underlying pathophysiological process is needed.

\section{Conclusion}

There was a significant correlation between IVF treatment and urogenital symptoms in menopause. Furthermore, the age of onset of menopause in IVF patients was found to be earlier. However, the differences are not clinically significant and require further research.

\section{Acknowledgments}

The authors would like to thank the Department of Obstetrics and Gynecology, Yasmin Clinic, for the opportunity to conduct this study.

\section{Funding}

The research was supported by University of Indonesia through PUTI Grant with contract NKB-1558/UN2.RST/ HKP.05.00/2020

\section{Disclosure}

The authors declare that they have no conflicts of interest in this work.

\section{References}

1. Jacobson MH, Chin HB, Mertens AC, Spencer JB, Fothergill A, Howards PP. "Research on infertility: definition makes a difference" revisited. Am J Epidemiol. 2018;187(2):337-346. doi:10.1093/aje/ kwx240

2. McKnight K, McKenzie LJ. Evaluation of infertility, ovulation induction and assisted reproduction. In: Feingold KR, Anawalt B, Boyce A, et al. editors. Endotext. MA: MDText.com, Inc. Copyright (C) 2000-2021; 2000

3. Jafarzadeh-Kenarsari F, Ghahiri A, Habibi M, Zargham-Boroujeni A. Exploration of infertile couples' support requirements: a qualitative study. Int J Fertil Steril. 2015;9(1):81-92.

4. Katsikis I, Kita M, Karkanaki A, Prapas N, Panidis D. Anovulation and ovulation induction. Hippokratia. 2006;10(3):120-127.

5. McGee EA, Hsueh AJW. Initial and cyclic recruitment of ovarian follicles. Endocr Rev. 2000;21(2):200-214.

6. Broekmans FJ. Testing for ovarian reserve in assisted reproduction programs: the current point of view. Facts Views Vis Obgyn. 2009;1(2):79-87.

7. Elder K, Mathews T, Kutner E, et al. Impact of gonadotrophin stimulation for assisted reproductive technology on ovarian ageing and menopause. Reprod Biomed Online. 2008;16(5):611-616. doi:10.1016/S1472-6483(10)60472-5

8. de Boer EJ, den Tonkelaar I, te Velde ER, Burger CW, van Leeuwen FE. Increased risk of early menopausal transition and natural menopause after poor response at first IVF treatment. Hum Reprod. 2003;18(7):1544-1552. doi:10.1093/humrep/deg278

9. Faddy MJ, Gosden RG, Gougeon A, Richardson S, Nelson J. Accelerated disappearance of ovarian follicles in mid-life: implications for forecasting menopause. Hum Reprod. 1992;7(10):1342-1346. doi:10.1093/oxfordjournals.humrep.a137570 
10. Goswami D, Conway GS. Premature ovarian failure. Hum Reprod Update. 2005;11(4):391-410. doi:10.1093/humupd/dmi012

11. Welt CK. Primary ovarian insufficiency: a more accurate term for premature ovarian failure. Clin Endocrinol. 2008;68(4):499-509. doi:10.1111/j.1365-2265.2007.03073.x

12. Dwi Susanti H, Chang PC, Chung MH. Construct validity of the menopause rating scale in Indonesia. Climacteric. 2019;22 (5):454-459. doi:10.1080/13697137.2019.1574737

13. Subrat P, Santa SA, Vandana J. The concepts and consequences of early ovarian ageing: a caveat to women's health. J Reprod Infertil. 2013;14(1):3-7.

14. Sunkara SK. Risk of Early Menopause following IVF Treatment. Assisted Reproduction Techniques. 2021:7-8. doi:10.1002/9781119622215

15. Heijnen EM, Eijkemans MJ, De Klerk C, et al. A mild treatment strategy for in-vitro fertilisation: a randomised non-inferiority trial. Lancet. 2007;369(9563):743-749. doi:10.1016/S0140-6736(07) 60360-2
16. Kim HK, Kang SY, Chung YJ, Kim JH, Kim MR. The recent review of the genitourinary syndrome of menopause. J Menopausal Med. 2015;21(2):65-71. doi:10.6118/jmm.2015.21.2.65

17. de Almeida Asencio F, Ribeiro HA, Ayrosa ribeiro P, et al. Symptomatic endometriosis developing several years after menopause in the absence of increased circulating estrogen concentrations: a systematic review and seven case reports. Gynecol Surg. 2019;16 (1):3. doi:10.1186/s10397-019-1056-x

18. Szmidt NA, Bhattacharya S, Maheshwari A. Does poor ovarian response to gonadotrophins predict early menopause? A retrospective cohort study with minimum of 10-year follow-up. Hum Fertil. 2016;19(3):212-219. doi:10.1080/14647273.20 16.1221149

\section{Publish your work in this journal}

The International Journal of Women's Health is an international, peerreviewed open-access journal publishing original research, reports, editorials, reviews and commentaries on all aspects of women's healthcare including gynecology, obstetrics, and breast cancer. The manuscript management system is completely online and includes a very quick and fair peer-review system, which is all easy to use. Visit http://www.dovepress.com/testimonials.php to read real quotes from published authors. 